\title{
Endurance and durability in biodiesel powered engines
}

\author{
J. Parrilla ${ }^{1}$, M. Muñoz ${ }^{2}$, F. Moreno ${ }^{2}$ \\ ${ }^{1}$ PHD Student (University of Zaragoza) \\ C/ Los Diputados, 17, $3^{\circ} \mathrm{B}$ \\ 50004 Zaragoza (Spain) \\ Phone: +34 976 444777, Fax: +34 976 444777, email: javipar2000@hotmail.com \\ 2 Department of Mechanical Engineering \\ Centro Politécnico Superior, University of Zaragoza \\ C/ María de Luna, 3 \\ 50018 Zaragoza (Spain)
}

\begin{abstract}
The use of fatty acids methyl esters either in mixtures with fossil diesel or in pure state in diesel engines is correlated to a series of technical problems which are to be taken into account in order to not spoil the important environmental and social advantages that this kind of biocombustibles reports. Throughout this work, in agreement with this fundamental premise and on the basis of the technical criteria of durability and resistance that so much affect engines, the most critical aspects of biodiesel use as well as their immediate consequences are introduced. Special emphasis is done on certain phenomena that condition the engine utility life, like the lubricating oil dilution and the deposits formation, as well as the storage and oxidative stability and finally the low temperature behaviour related to engine operation in greater or smaller degree incompatible with biodiesel (fatty acid methyl esters). To sum up, a study in depth will be realized about some of the most problematic aspects referred to biodiesel use, analysing its entire technical dimension and contributing possible solutions. In general, this work tries to be a guide, which allows to identify the most sensible areas within the engine, as well as the suitable means and solutions for the correct use of biodiesel in compression ignition engines (diesel engines).
\end{abstract}

\section{Key words}

Biodiesel, deposit, dilution, durability, stability, additive

\section{Introduction to the problem of fuelling with biodiesel}

The engine resistance and the consequent overcoming of the durability test are two of the major issues that must be considered within the power sector of production and consumption of biodiesel, in relation to assuring and guaranteeing the suitable use of this carburant (methyl ester of vegetal oils) in compression ignition engines (CIE), as well denominated diesel engines.

Among the most important items that would be necessary to correct in order to achieve a good operation with such biocarburants, several researchers [1] recommend the elimination of the subsequent list of compounds, which might affect both resistance and durability of the engine: monoglycerids, unreacted di- and triglycerids, unreacted free fatty acids, and not eliminated methanol and glycerol, as well as absorbed water. P. Gateau et al. [2] add to the list the following group of potentially harmful substances for the engine, namely, salts, phospholipids and strong acids from catalytic origin

Triglycerids and diglycerids are greases from vegetal or animal origin, which have not completed the transesterification process, and that when being dissolved in biodisel their presence supposes an extra difficulty in relation to the combustion process. Due to their nature as fats, their behaviour is analogous to which some vegetable biooils experience when being used as fuels for diesel engines: the soot deposit formation (coke) on the injectors, certain components of the piston (rings) and in the interchange ports (inlet and outlet valves).

The rest of the elements mentioned by Graboski [1], namely, monoglycerids, fatty acids, glycerol, methanol and water, present the disadvantage of corroding and wearing 
out metallic bearings and other mechanical pieces that are in permanent movement and contact.

On the other hand, it is also possible to emphasize and stress some of the less favourable properties associated to biodiesel use. Among most decisive ones the elevated boiling point and the high viscosity of methyl esters, what negatively affect combustion process in low load conditions, thus entailing two immediate consequences [1].

The portion of biodiesel that has not completed the combustion process is forced past the rings of the cylinder until reaching the crankcase, where it dissolves with the lubricating oil thus diminishing its viscosity (followed by a thickening, presence of soot and a decrease of the antioxidants concentration) and, in general, the lubricant properties of lube oil. This problem could be avoided at least partially adapting both the angles and the diameter of the injector orifices [2]. The presence of organic rests in the lubricating oil causes anomalous changes in some of its major characteristics, as for example an increase in the acidity derived from the organic degradation of biodiesel. As a negative element regarding this dissolution process it can be emphasized the fact that the elevated boiling point of biodiesel, mixed with the lubricating oil, does not facilitate its own evaporation with the heating produced by the engine; which, in affirmative case, would make possible the elimination of the residual biodiesel through an easier and simpler way. This dilution process of lubricating oil in biodiesel takes place in general as a consequence not of the known phenomenon of blow-by, but by the normal drag process of certain fractions of biodiesel that are carried out by the pistons rings. It is normal to register important viscosity losses (lubricant property) on lube oil after relatively few running hours whether the engine or the diesel-biodiesel mixture does not perfectly fit to the suitable parameters. Biodiesel derived from very unsaturated oils or raw materials (sunflower, olive oil, soybean) tends to give greater degrees of dissolution in lubricating oil because its boiling point is higher than that of methyl esters elaborated from saturated fats (palm, animals fats, coconut). Justification to this phenomenon exactly lies in the greater calorific energy, which is required to break multiple bonds in comparison to the simple ones from saturated fats. In synthesis, palm oil biodiesel burns better than another one synthesized from soybean or sunflower oil, what will subsequently generate a lower dissolution rate on the lubricating oil. Therefore, a partial solution to this problem is suggested to be the additivation of biodiesel with a small percentage (to define) of methyl ester highly saturated, which would improve the combustion eradicating or diminishing the problem. In his report on biodiesel from "sativa camelina" A. Fröhlich et al. [5] talk about the accumulation of important amounts of methyl esters in the lubricating oil, reaching levels up to $16 \%$ at the end of $8,000 \mathrm{~km}$ tests. Simultaneously, the viscosity of lubricating oil submitted to the mentioned kilometric tests underwent reductions of $30 \%$ due to ester dilution in lube oil.
The unburned biodiesel fraction not mixed with the lubricating oil in engine crankcase is deposited on the air box cover, on the injectors (Figure 1), rings and valves, as well as on the top of the cylinder shirts. Finally it undergoes a process of carbonization of undesirable consequences. These deposits happen generally at average load (at full load combustion becomes more homogenous and perfect) when the low fuel volatileness causes it not to burn and therefore to be deposited on the surfaces suffering a formation process of coke and soot [1]. Soot deposits are the result of the imperfect fuel combustion (due to the high boiling point), but also sometimes has their origin in drying and later carbonization of remains of lubricating oil. Deposition of residual material on the surfaces of mechanical pieces also adopts a second type of structure formed by lacquers (lacquering); defined these ones as hard, dry deposits, generally gleaming and insoluble in oil, and that in addition they are not easily eliminated with water [7]. On the other hand, as a solution to this topic, biodiesel distillation remarkably reduces the tendency of deposits formation, by eliminating the less volatile fractions from biodiesel [2].

As a conclusion, it is observed that at full load biodiesel generally has a more perfect combustion, which directly implies a lower dilution rate of methyl esters into the lubricating oil as well as a decrease in the deposit formation. The solvent property of biodiesel does not only show up with the lubricating oil but that it also reflects its detrimental effect on fuel line elastomers or even other materials like lacquers and paintings from vehicles bodieworks or fuel tanks' baths or layers.

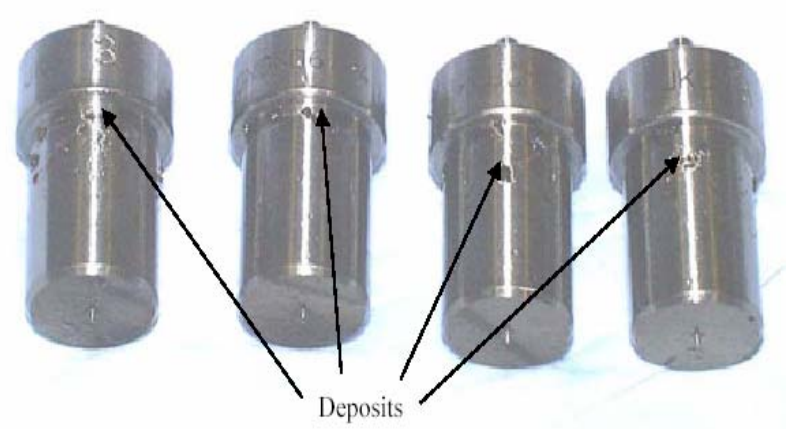

Fig. 1. Carbon build-up on the injector nozzles [7]

On the other hand, it is very well known that low temperature behaviour and the outstanding oxidative and storage instability are among the two most important technical difficulties in relation to biodiesel use. The latter property generates the fuel oxidation producing degradations such as hydroperoxids or carboxylics acids, which generate rubbers, conferring on the biocombustible a plastic and viscous behavior. 
A possible solution to improve biodiesel low temperature behaviour and at the same time to diminish its boiling and flash point would consist in the addition of certain alcohol (metanol, ethanol) in a variable percentage according to the technical and environmental specifications in which engine operation is pretended to be assessed. The immediate result is an improvement in the above mentioned problems of lube oil dilution and deposits formation; although certain power loss would also be registered as an important and negative consequence, always proportional to the amount of added alcohol [2].

\section{Immediate consequences of the use of biodiesel in internal combustion engines}

The only means that allow to tackle suitability of biodiesel in compression ignition engines with enough guarantees of success is the development of durability studies extended to several hundreds of hours (200, 5001000 hours), thus being able to reproduce the behavior of this biocombustible in approximate conditions to those being actually developed, whether it be slow motion, total load or intermediate powers.

Some of the most significant symptoms and consequences that are shown at the end of these durability studies are enumerated next [1]:

\section{A. Fuel quality}

Low return pressure of biodiesel. A blackening of the biocombustible is parallelly observed.

\section{B. Power loss}

Engine power diminution with regard to the beginning of the durability study due to multiple technical reasons, among others, the flow decrease through the fuel conduction system by partial clogging of itself with the corresponding low biodiesel consumption at the end of the test.

\section{Leaks from chamber}

Appearance of leaks from combustion chamber towards crankcase (phenomenon known as blow-by). As combustion takes place, the high pressure of the combustion chamber forces the mixture of fuel, air, moisture and gases to pass through the rings of the piston in direction towards the lubricating oil of the crankcase. These rings would have to maintain a good adjustment to be able to contain the pressure and thus to transmit all the energy to the connecting rod. The causes by which these leaks or blow-by process take place derive from the wearing down of rings and cylinder sleeves caused by prolonged use. This process takes place in the mentioned rings of the piston as a product of the accumulation of soot and deposits of unburned rests of biodiesel.

\section{Durability and endurance reduction due to oxidation stability}

The influence of oxygen and ambient air is known under the term oxidative stability. Thermal stability describes the impact of temperature in the absence of oxygen, whereas storage stability covers the effects of time and storage conditions. However, for the final version of EN 14214 only a thermal oxidative parameter (the Rancimat induction period) could be included in, as at this time no suitable analytical procedures for the determination of thermal and storage stability were available. To solve this situation of lack of knowledge, a European project called "Stability of Biodiesel” (BIOSTAB) was initiated, and the European commission mandated the project partners to come up with viable test methods and limits for the missing parameters.

A minimum Rancimat induction period of six hours is defined for biodiesel samples within EN 14214. This limit corresponds to the period of time passing before fatty acid methyl esters, aged at $110^{\circ} \mathrm{C}$ under a constant air stream, are degraded to such an extent that the formation of volatile acids can be recorded through an conductivity increase. The minimum induction period of six hours has to be considered as a compromise between engine and injection pump manufacturers on the one hand and biodiesel producers on the other. Experts hold that it will be very difficult to meet this limit for biodiesel fuels derived from many common raw materials, unless antioxidants are added to the FAME.

This fatty acid methyl esters are more sensitive to oxidative degradation than fossil diesel due to its high content of polyunsaturated esters, as the methylene groups adjacent to double bonds turns out to be particularly susceptible to radical attack. Therefore, seed oils rich in linoleic and linolenic acid -such as sunflower oil - tend to give methyl ester fuels with poor oxidation stability, whereas highsaturated fuels - such as palm or coconut oil methyl esters - generally show improved stability.

Hydroperoxides produced during the initial stage of oxidative degradation are suspected of attacking elastomers within the fuel line system, causing an increase in peroxide value, which thus serves as an indicator of the progress of fuel oxidation. Moreover, hydroperoxides also increase cetane number, which might explain marked reductions in hydrocarbon and carbon monoxide emissions of mildly oxidized biodiesel fuels. However, these primary products of fuel oxidation are not stable, but are degraded according to two different reaction pathways. On the one hand, hydroperoxides may polymerize with other free radicals to form insoluble sediments and gums, which are associated with fuel filter plugging and deposits within the injection system and the combustion chamber. These changes are accompanied by an increase in viscosity observable in oxidized biodiesel samples. On the other hand, further 
oxidation of primary oxidation products results in the formation of aldehydes, ketones and short-chain carboxylic acids, linked with corrosion of the injection system. These changes cause an increase in acid value and a correspondingly slower increase or even a decrease in peroxide value.

Besides the fatty acid composition of the feedstock, also the content of natural antioxidants, such as tocopherols and carotenes, bas been identified as a crucial factor for the oxidative stability of a given biodiesel sample. In general, antioxidant concentrations are high for undistilled fuels prepared from fresh vegetable oils, whereas hardly any antioxidants are contained in distilled samples, as they have been removed during distillation. Moreover, antioxidants are also consumed during the frying process, explaining the slightly lower contents for biodiesel fuels derived from recycled frying oil; and they are only contained in small quantities in animal fat.

The addition of synthetic antioxidants has been identified as a viable means of improving oxidation stability, especially those derived from tert-butyl hydrochinone (TBHQ), 2,6-di-tert-butyl-4-methyi-phenol (BHT), pyrogallol, propylgallate and several new synthetic phenolic antioxidants. However, as the Rancimat induction period bas been found to decrease significantly during storage, antioxidants might have to be added in comparatively high concentrations to ensure that fuels will still meet the specifications at the filling station.

In the standard analytical method for the determination of biodiesel oxidation stability (Rancimat apparatus) a fuel sample is aged at elevated temperature $\left(110^{\circ} \mathrm{C}\right)$ by passing air through it at a constant rate. The effluent gases are collected in a measuring cell filled with distilled water, of which the conductivity is constantly measured. Once hydroperoxides as primary oxidation products are reacted (in water) into volatile acids (mainly formic and acetic acid), conductivity values steeply increase. The period of time up to this point is called induction period (IP) and is expressed in hours. Systematic tests showed that Rancimat induction period is well correlated with other biodiesel quality parameters, such as peroxide value, kinematic viscosity, ester content, acid value, and polymer content.

Within the European specifications the value for the oxidative stability, expressed as the induction period using a Rancimat instrument, has to be higher than $6 \mathrm{~h}$ and should be guaranteed during the whole supply chain of the fuel. However, the stability of biodiesel varies significantly depending on the feedstock as well as the process technology. Biodiesel produced from rapeseed oil shows higher induction periods, whereas biodiesel produced from used frying oil, sunflower oil, soybean oil or animal fat had similar or significantly lower values for the induction period.
A reason for this is the different fatty acid composition among the feedstocks and of course the different content of natural antioxidants. Therefore, in the future most of the biodiesel produced will have to be additivated with appropriate antioxidants. Thus different commercially available natural and synthetic antioxidants were tested in order to improve the oxidative stability of biodiesel. Furthermore, the influence of the most effective antioxidants was investigated in order to find appropriate additives to improve oxidation stability without deterioration of the other parameters. Finally a screening of the most promising antioxidants was carried out to evaluate the optimum antioxidant amount.

Following list of antioxidants is commercially available at a reasonable price and all they offer a relevant tool of improving the oxidation stability. There are two groups, on one hand the synthetic antioxidants, and on the other hand the natural antioxidants which are present in vegetable oils enabling its own conservation and improving naturally its stability:

\section{A. Synthetic antioxidants}

Ethoxiquin

Tert-butyl hidroquinone (TBHQ)

Di-tert-butyl-metilphenol (BHT)

Tert-butyl-methoxyphenol (BHA)

Propyl gallate

Pyrogallol

L-ascorbyl palmitate

Tert-butyl-methylphenol (t-BHT)

\section{B. Natural antioxidants (tocopherols, carotenes)}

Covi Ox T50/T70

Copherol F1300

Controx VP

Dadex TRC

Biocaps ER/LT/PA/A70/GP

In order to get information about the efficiency of the selected antioxidants, to each of the different biodiesel samples $1000 \mathrm{mg} / \mathrm{kg}$ antioxidant was added.

Regarding solubility results showed that those antioxidants containing ascorbic acid 6-palmitate were insoluble in biodiesel and therefore were not suitable as additives. Furthermore, most of the synthetic antioxidants were totally insoluble in fully additivated, winterised fossil diesel, but no negative effects (e.g. formation of deposits) in blends with biodiesel could be observed even at low temperature in blends containing 2, 5, and $20 \%(\mathrm{v} / \mathrm{v})$ of additivated biodiesel. 
All above referred antioxidants were tested at a concentration of $1000 \mathrm{mg} / \mathrm{kg}$ with two different types of methyl esters: RME from raps and COME from used cooking oil. Aim of this screening was to evaluate the most effective products from all showed. In Table 1 every induction period attained for each antioxidant is presented to be able to select the most suitable ones.

\begin{tabular}{|c|c|c|c|}
\hline Antioxidant & $\begin{array}{c}\text { Concentration } \\
{[\mathrm{mg} / \mathrm{kg}]}\end{array}$ & $\begin{array}{c}\text { RME } \\
\text { Induction Period } \\
{[\mathrm{h}]} \\
\end{array}$ & $\begin{array}{c}\text { COME } \\
\text { Induction Period } \\
{[\mathrm{h}]}\end{array}$ \\
\hline Reference & & 9.15 & 5.92 \\
\hline TBHQ & 1000 & 38.53 & 29.44 \\
\hline Propylgallat & 1000 & 27.36 & 29.90 \\
\hline Pyrogallol & 1000 & 26.81 & 31.95 \\
\hline $\mathrm{BHA}$ & 1000 & 24.30 & 13.80 \\
\hline BIOCAPS GP & 1000 & 18.02 & 17.94 \\
\hline CoviOx T50 & 1000 & 10.88 & 11.48 \\
\hline Tenox 20 & 1000 & 10.83 & 9.42 \\
\hline AP & 1000 & 10.61 & 4.91 \\
\hline Di-t-BHT & 1000 & 10.54 & 7.23 \\
\hline Covi-Ox T70 & 1000 & 10.46 & 12.46 \\
\hline Controx VP & 1000 & 10.32 & 10.81 \\
\hline $\mathrm{t}-\mathrm{BHT}$ & 1000 & 9.85 & 10.84 \\
\hline Copherol 1300 & 1000 & 9.82 & 6.77 \\
\hline Ethoxyquin & 1000 & 9.78 & 8.49 \\
\hline Dadex & 1000 & 9.69 & 10.52 \\
\hline Rendox & 1000 & 9.28 & 11.46 \\
\hline BIOCAPS A-70 & 1000 & 8.54 & 10.16 \\
\hline BIOCAPS TL & 1000 & 8.42 & 6.42 \\
\hline BIOCAPS ER & 1000 & 8.38 & 6.17 \\
\hline BIOCAPS PA & 1000 & 7.40 & 6.51 \\
\hline
\end{tabular}

It can be shown that in both biodiesel samples pyrogallol (PY), propylgallate (PG) and TBHQ were the most effective antioxidants leading to induction periods from 26.81 to 38.53 , which means that the induction period was increased by these factors. In general, addition of synthetic antioxidants had a strong influence on the stability, whereas on the other hand, antioxidants on the basis of natural products showed only small or even negative effects. Such negative effects can be explained by the fact that antioxidants under certain conditions (especially at high concentrations) could have pro-oxidative properties. Furthermore, the volatility of antioxidants should be kept in mind, reason whereby antioxidant effect might have been reduced.

Among the natural antioxidants, Biocaps GP seems to be the most effective one, but it has to be considered that the product contains also about $30 \%$ of PG.

Apart from all the properties mentioned above which involve some of the parameters of the European Standard EN 14214, on the whole, additivation with any kind of antioxidants does not lead to any significant change in biodiesel quality most critical parameters, except for any singular case which should be studied particularly.

However, in order to minimize potential negative effects, it is recommended to use antioxidants at the lowest possible concentrations

\section{Durability and endurance reduction due to low temperature behaviour}

The behavior of fuels under low ambient temperatures is an important quality criterion in regions of temperate and arctic climates. Partial solidification in cold weather may cause blockages of fuel lines and filters, leading to problems during engine start-up and injection in heating burners. For the assessment of cold-temperature properties of biodiesel and fossil diesel fuel various parameters have been suggested, including cloud point (CP), pour point (PP), cold-filter plugging point (CFPP) and lowtemperature flow test (LTFT).

Cloud Point It denotes the temperature at which first visible crystals are formed within a fuel sample when it is cooled, is to be determined according to EN 23015.

Pour Point It stands for the lowest temperature to which the sample may be cooled while still retaining its fluidity, can be obtained via ASTM D 97. Pour point is a measure of the fuel gelling temperature, at which the fuel can no longer be pumped. Neither of these parameters is considered as a reliable tool for predicting actual engine operability limits, and they are not included in the new EU biodiesel norm. However, EN 590 provides indicative limits for cloud points of fossil fuels used in arctic climates, which are to be specified by the member states.

Cold-Filter Plugging Point It describes fuel filterability at low ambient temperatures and is commonly considered to be a suitable indicator of operability limits. The CFPP test protocol is used in Europe (EN 116) and it defines a highest temperature at which a fuel portion fails to pass a standardized filtering device within a specified amount of time when cooled under standardized conditions.

Low-Temperature Flow Test It is related to the same property mentioned by CFPP, which involves fuel pass through any filter under certain low temperature restrictions. LTFT procedure is preferred in the USA (ASTM D 4539). However, as the ASTM procedure prescribes more stringent test conditions, LTFT values are always more restrictive than the corresponding CFPP readings for the same sample. 
Comparison of CFPP and LTFT results to other coldtemperature parameters has shown that both correlate with cloud points of fuel blends containing at least $10 \%$ of biodiesel, what indicates the real physical importance of this last parameter, the CP. Furthermore, whereas LTFT is not included in either of the discussed fuel quality standards, CFPP is a limited parameter with identical indicative limits for both biodiesel and fossil diesel.

In general, biodiesel is always set one step back compared to fossil diesel regarding coldflow properties, as is shown in Table 3, listing typical cloud point, pour point and CFPP values.

TABLE 3. - Cloud points, pour points and cold-filter plugging points of fossil diesel and FAME from different raw materials.

\begin{tabular}{lcccccc}
\cline { 2 - 6 }${ }^{\circ} \mathbf{C}$ & DIE. & RAPE & SUNF. & SOYA & PALM & TALL. \\
\cline { 2 - 6 } $\mathbf{C P}$ & -15 & -2 & -1 & 0 & -13 & 14 \\
\hline $\mathbf{P P}$ & -33 & -9 & -3 & -2 & - & 12 \\
\hline $\begin{array}{l}\mathbf{C F P} \\
\mathbf{P}\end{array}$ & -18 & -15 & -3 & -2 & -1 & 13 \\
\hline
\end{tabular}

Melting points of neat fatty acid methyl esters depend on chain length and the degree of unsaturation, with longchain saturated compounds displaying particularly unfavorable cold-temperature behaviour (Table 4). Thus neat biodiesel fuels derived from materials rich in these compounds (such as methyl esters of palm oil or tallow) might even pose problems at room temperature, unless precautionary measures, such as heating fuel tanks, fuel lines and filters, are taken.

TABLE 4. - Melting point variation with chain length and unsaturation degree.

\begin{tabular}{cc}
\cline { 2 - 2 } & \multicolumn{1}{|c}{ MELTING POINT ${ }^{\circ} \mathrm{C}$} \\
\hline $\mathbf{C 1 2 : 0}$ & +5 \\
\hline $\mathbf{C 1 4 : 0}$ & +19 \\
\hline $\mathbf{C 1 6 : 0}$ & +30 \\
\hline $\mathbf{C 1 8 : 0}$ & +39 \\
\hline $\mathbf{C 1 8 : 1}$ & -20 \\
\hline $\mathbf{C 1 8 : 2}$ & -35 \\
\hline $\mathbf{C 1 8 : 3}$ & -46 \\
\hline $\mathbf{C 2 2 : 1}$ & -1 \\
\hline
\end{tabular}

From both Table 3 and Table 4 it is derived that if liquid FAME are cooled, long-chain methyl esters -as esters of stearic and palmitic acid- are among the first to precipitate and therefore typically constitute a major share of material recovered from clogged biodiesel filters. Besides, also unsaturated mono- and diglycerides are linked with an increased tendency for causing filter blockage in biodieselfuelled vehicles. Apart from the fact that crystal formation starts at considerably higher temperatures in biodiesel than in fossil diesel fuels, also the rate of crystal growth seems to be accelerated. Thus in contrast to fossil diesel samples, some biodiesel fuels display only a small difference between cloud point and pour point.

One of the most commonly used ways for improving cold temperature behaviour is the addition of substances, resulting in blends with improved cold-flow properties. Here blending fatty acid methyl esters with fossil diesel is considered to be the most promising method, as it is comparatively cheap, does not involve an extra processing step, and the resulting fuel blends will not pose problems in engine operability.

An alternative strategy would be the addition of cold-flow improvers used in the petrodiesel industry. These additives, covering a wide range of chemical compounds, impede crystal growth in cooled fuels and thus effectively depress pour points, whereas the effect on such an important parameter as the cloud point is limited. Therefore, it has been established that viable methods for the improvement of coldtemperature filterability in FAME are to be concentrated on cloud point rather than pour point, as most crystallization processes start up at cloud point temperatures affecting seriously to fluidity of biodiesel. Thus the sole addition of pour point depressants will not always show the desired effects.

As result of works made in search of most commonly used cold-flow improvers, next commercial products were found to be the most effective ones in biodiesel and of course in fuel diesel treatments as well:

\section{Lubrizol 7671 (PP depressant) Wintron XC30 (PP depressant) Chimec (CFPP additive) Infineum 6635(CFPP additive)}

From the chemical point of view, numerous additives have been synthesized and reported mainly in the patentliterature, which have the effect of lowering CP and PP. These additives are usually a variety of viscositymodifying polymers such as:

carboxy-containing interpolymers, Styrene-maleic anhydride copolymer Polymethacrylates 
Polyacrylates

Nitrogen-containing polyacrylates

Similar additives have also been tested for conventional diesel fuel. The beneficial effect of some additives appears to be limited, however, because they more strongly affect the PP than the CP, and the CP is more important than the $\mathrm{PP}$ for improving low-temperature flow properties as mentioned above.

A totally different approach to the problem is the modification of the chemical structure of the fuel. So methanol as the alcohol used for transesterification has been replaced by longer or secondary alcohots. The resulting long-chain or branched-chain esters show considerable advantages regarding pour points, and moderate benefits in CP and CFPP (Table 5).However, as the alcohols are far more expensive than methanol and as the production of long- or branched-chain esters will involve costly procedures, this strategy is not considered as feasible. Alternatively, also more suitable compounds might replace the fatty acid of the FAME. So it was suggested the addition of short-chain fatty acid methyl esters, isolated from transesterified coconut oil, whereas on the other hand the development of soybean varieties low in palmitic acid, as the main longchain saturated compound in soybean oil, was discussed as well.

TABLE 5. - Influence of choice of alcohol used in transesterification of tallow on cold-flow parameters.

\begin{tabular}{cccc}
\cline { 2 - 3 } & CLOUD POINT & POUR POINT & CFPP \\
\cline { 2 - 3 } Methyl esters & 17 & 15 & 9 \\
\hline Ethyl esters & 15 & 12 & 8 \\
\hline 1-Propylesters & 12 & 9 & 7 \\
\hline 1-Butylesters & 9 & 6 & 3 \\
\hline 2-Butylesters & 9 & 0 & 4 \\
\hline
\end{tabular}

Finally various methods have been proposed for the partial removal of saturated compounds from biodiesel to produce fuels enriched in unsaturated fatty acid methyl esters. It was suggested to mix biodiesel with an aqueous urea solution, utilizing the fact that saturated fatty acid methyl esters form more stable solid urea compounds than unsaturated ones. After the separation of the solid fraction, the remaining fuel shows considerably improved cold-temperature properties.

Winterization is a strategy originally stemming from the food industry, where it serves as a method for facilitating easier handling and pouring of salad oils. During winterization FAME mixtures are equilibrated at a temperature between their cloud point and pour point, followed by repeated removal of precipitated crystals via filtration or centrifugation. Problems connected with this procedure are the fact that also unsaturated esters are lost, when they are entrapped within precipitating crystals, and that the effects of this process on fatty acid methyl esters derived from some raw materials are limited due to the small differences between cloud point and pour point. Thus two modifications to the conventional winterization procedure have been suggested: mixing the esters with an organic solvent (e.g. hexane) prior to winterization prevents occlusion of unsaturated compounds, whereas the addition of pour point depressants prior to winterization might enhance the operability of this procedure by attaining a larger field of temperatures.

Nevertheless, both winterization and the removal of saturated compounds in the form of urea complexes are considered ineffective. On the one hand their yields tend to be low. On the other hand, it is important not to remove the entire saturated biodiesel fraction, as saturated fatty acid methyl esters have considerable advantages regarding ignition quality and heating value.

\section{References}

[1] M.S. Graboski y R.L. McCormick. Combustión of fat and vegetable oil derived fuels in diesel engines. Prog. Energy Combust. Sci. Vol. 24, 125-164. Elsevier (1998)

[2] P. Gateau, J.C. Guibet, G. Hillion y R. Stern. Utilisation des huiles végétales et de leurs produits de transestérification comme carburants diesel. Revue de l’Institut Français du Pétrole, Vol. 4, Nº4, juillet-août (1985).

[3] Stability of biodiesel, Presentation of the Biostab Project Results (2003)

[4] G. Knothe, R.O. Dunn, M.O. Bagby, Biodiesel: The use of vegetable oils and their derivatives as alternative diesel fuels, U.S. Department of Agriculture

[5] A. Fröhlich y B. Rice. Evaluation of Camelina sativa oil as feedstock for biodiesel production. Industrial crops and products 21 (2005) 25-31.

[6] S. Schober, M. Mittelbach, The impact of antioxidants on biodiesel oxidation stability, European Journal of Lipid Science and Technology (2004)

[7] B. Terry. Impact of biodiesel on fuel system component durability. The Associated Octel Company Limited (UK). Septiembre (2005).

[8] M. Mittelbach, C. Remschmidt, Biodiesel, the comprehensive handbook, (2004) 
